\title{
66 Yaşında Kadın Hastada Yeni Tanı ALCAPA Sendromu
}

\author{
Murat KERKÜTLÜOĞLU, Enes ÇELIKK, Bayram ÖZTÜRK, Hakan GÜNEŞ
}

Kahramanmaraş Sütçü İmam Üniversitesi Tıp Fakültesi, Kardiyoloji Anabilim Dalı, Kahramanmaraş.

\section{ÖZET}

Sol koroner arterin pulmoner arterden (ALCAPA) anormal kökeni, nadir görülen doğuştan kalp anomalisidir. Genellikle klinik seyir; ileri sol kalp yetmezliği ve yaşamın ilk aylarında ortaya çıkan mitral kapak yetersizliğidir. Bununla birlikte, bazı durumlarda sağ koroner arterden oluşan kollateraller miyokard perfüzyonu için yeterlidir. ALCAPA'lı hastalarda aritmi veya erişkin yaşamda ani kalp ölümü ilk klinik başvuru olabilir. Göğüs ağrısı ve çarpıntı şikayetleri ile acil servise başvuran ve sol koroner arterde anormal köken saptanan 66 yaşında kadın hastayı sunmaktayı.

Anahtar Kelimeler: L-ALCAPA. Koroner anomali. Kardiyak arrest. Yetişkin.

New Diagnosis ALCAPA Syndrome in a 66-Year-Old Woman

\begin{abstract}
Abnormal origin of the left coronary artery from the pulmonary artery (ALCAPA) is a rare congenital heart anomaly. Usually the clinical course; advanced left heart failure and mitral valve insufficiency that occurs in the first months of life. However, in some cases collaterals consisting of the right coronary artery are sufficient for myocardial perfusion. Arrhythmia or sudden cardiac death in adult life may be the first clinical presentation in patients with ALCAPA. We present a 66-year-old female patient who was admitted to the emergency department with complaints of chest pain and palpitations and was found to have an abnormal origin in the left coronary artery.
\end{abstract}

Key Words: L-ALCAPA. Coronary anomaly. Cardiac arrest. Adult.

Pulmoner arterdeki anormal sol koroner arter (ALCAPA; Bland-White-Garland sendromu olarak da adlandırılır), kalp gelişiminin erken evrelerinde koroner arter malformasyonunun neden olduğu nadir, doğuştan kalp anomalisidir. ALCAPA bebeklik döneminde uygun şekilde tedavi edilmedikçe, sol koroner arter (LCA) bölgesindeki miyokard iskemisi ve iskemik mitral yetersizliği nedeniyle yaşamın ilk y1lında genellikle ölümle sonuçlanmaktadır. Ancak, sağ koroner arterden (RCA) LCA'ya kollateral dolaşımın gelişmesi durumunda yetişkinlerin semptomsuz olarak hayatta kaldıkları bildirilmiştir. Bununla birlikte kalp

Geliş Tarihi: 17.Mart.2020

Kabul Tarihi: 02.Eylül.2020

Dr. Murat KERKÜTLÜOĞLU

Kahramanmaraş Sütçü İmam Üniversitesi Tıp Fakültesi, Kardiyoloji Anabilim Dalı,

Kahramanmaraş.

Tel:0505 7733009

E-posta: drmuratkerk@gmail.com

Yazarların ORCID ID Bilgisi:

Murat KERKÜTLÜOĞLU 0000-0003-1007-0574

Enes ÇELIKK 0000-0002-4540-7571

Bayram ÖZTÜRK 0000-0001-7014-6484

Hakan GÜNEŞ 0000-0003-3853-5046 yetmezliği ve ani kardiyak ölümü önlemek için cerrahi tedavi esastır.

\section{Olgu Sunumu}

Acil servise ani başlangıçlı göğüs ağrısı ve çarpıntı şikayeti ile başvuran, daha önce bilinen bir hastalığ1 olmayan 66 yaşında kadın hastanın elektrokardiyografisinde atriyal fibrilasyon görülmüş ve monitör takiplerinde non-sustained ventriküler taşikardi atakları izlenmiştir. Başvuru sonrası yapılan tetkikleri sırasında kardiyak arrest gelişmesi üzerine 17 dakika uygulanan etkin kardiyopulmoner resüsitasyon sonrasında da non-sustained ventriküler taşikardi ataklarının devam ettiği görülmüştür. Kardiyak oskültasyonda sol sternal sınırda sürekli üfürüm saptanmıştır. Laboratuvar incelemesinde; high sensitivity (hs) Troponin $1.3 \mathrm{ug} / \mathrm{L}$, kreatin kinaz-MB(CK-MB) 12.9 ug/L, brain natriüretik peptid (BNP) $4900 \mathrm{ng} / \mathrm{L}$ olarak tespit edilmiştir. Arteryel kan basıncı 100/55 mmHg, kalp hızı ise 124/dk olarak değerlendirilmiştir. Entübe takip edilen hasta, akut koroner sendrom olarak değerlendirilmiş ve acil koroner anjiyografi işlemi planlanarak $600 \mathrm{mg}$ klopidogrel ile $300 \mathrm{mg}$ asetilsalisilik asit yüklemesi yapılarak koroner anjiyografi laboratuvarına alınmıştır. Yapılan koroner anjiografide 
M. Kerkütlüoğlu, ark.

RCA'nın sağ koroner ostiumdan çıktığı görülürken LMCA görüntülenememiştir. RCA ileri ektazik olarak değerlendirilmiştir (Şekil-1). Koroner çıkış anomalisi düşünülen hasta nefroloji kliniğinin önerileri ile 6 saat hidrasyon sonrası kardiyak bilgisayarlı tomografik anjiyografi ile ileri değerlendirmeye alınmış ve ana pulmoner arterden kaynaklanan anormal LMCA varl1ğ1 ortaya çıkarılmıştır (Şekil-2). LMCA'nın sol sinüs valsalva yerine pulmoner arterden orjin aldığı ve LALCAPA sendromu ile uyumlu olduğu görülmüştür. Ko-dominant koroner dolaşım tespit edilirken, LMCA'nın anormal olarak ana pulmoner arterin kapakçık seviyesinin yaklaşık $1 \mathrm{~cm}$ üzerinden orjin aldığı tespit edilmiştir. Sol anteriyor desendan arter (LAD) proksimal ve mid segmentte ektazik $(9.3 \mathrm{~mm})$ olup lümen patentti ancak kalp apeksine yakın distal kesimlerde çapı belirgin olarak azalmakta ve intramyokardiyal seyir göstermekteydi (Şekil-3). Sirkumfleks arter (LCx) seyri boyunca ektazik (6,5 $\mathrm{mm}$ ) olup cidarı doğaldı. Sağ ve sol koroner dolaşım arasında kalp çevresinde ve mediastende çok sayıda kollateral vasküler yapılar izlenmekteydi (Şekil-4). Transtorasik ekokardiyografi ile yapılan değerlendirmede sol kalp boşlukları dilate izlenmiştir. Sol ventrikül ejeksiyon fraksiyonu $\% 42$ olarak ölçülmüş, renkli doppler incelemesinde orta seviye mitral yetmezliği tespit edilmiş ve sol atrium çapı 46 $\mathrm{mm}$ ile dilate izlenmiştir. . Entübe takip edilen hastanın hemodinamik parametreleri ve kan gazı takiplerinin optimum seyretmesi üzerine ekstübe edilmiş ve hastaya LMCA'nın aortaya tekrar yerleştirilmesi operasyonu önerilmiştir. Hastanın operasyonu reddetmesi üzerine; intrakardiyak defibrilatör tedavisi planlanmıştır. $\mathrm{CHA}_{2} \mathrm{DS}_{2}$-VASc skoru 2 olan hastaya varfarin tedavisi başlanmış ve klopidogrel $75 \mathrm{mg}$, asetilsalisilik asit $100 \mathrm{mg}$, metoprolol $50 \mathrm{mg}$, atorvastatin $20 \mathrm{mg}$, ramipril $5 \mathrm{mg}$ olarak düzenlenen medikal tedavi ile hasta taburcu edilmiştir.

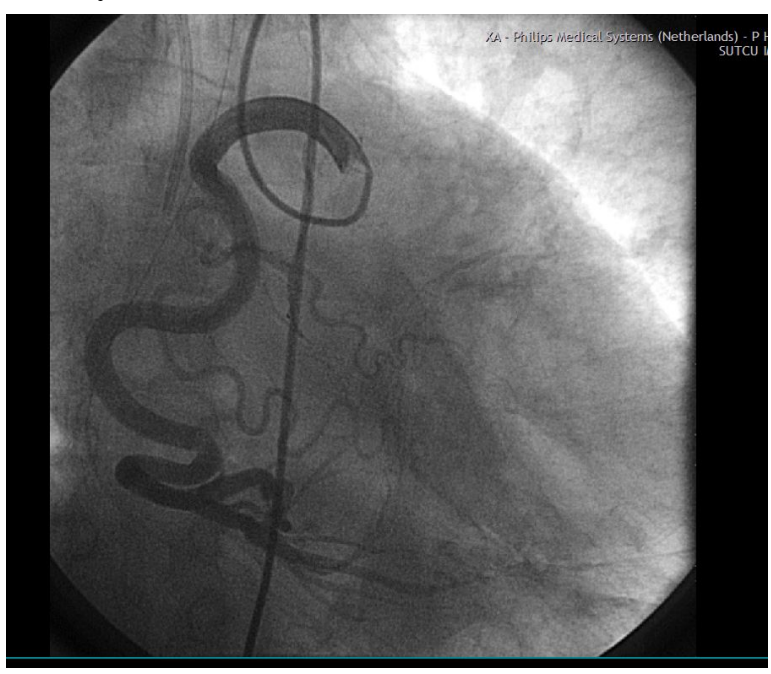

Şekil 1.

Koroner anjiyografide ektazik $R C A$.

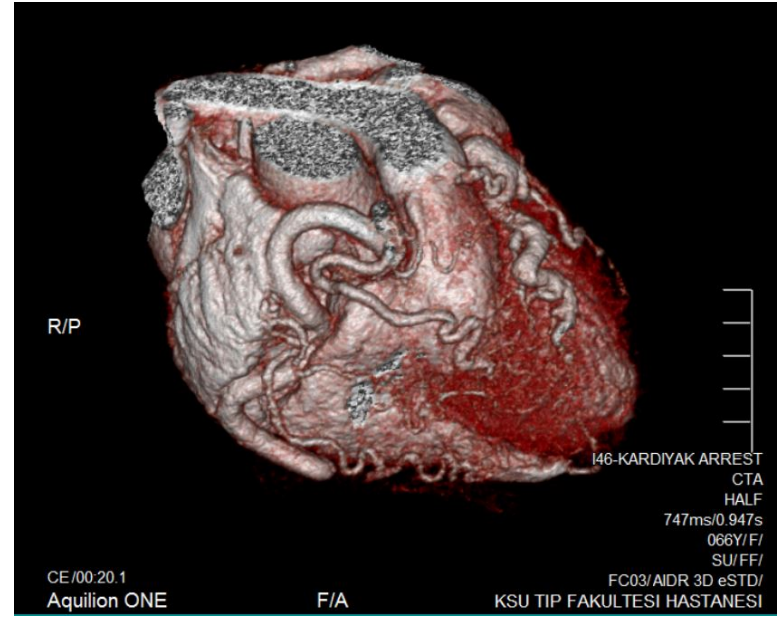

Şekil 2.

Koroner BT Anjiyografi görüntüsü

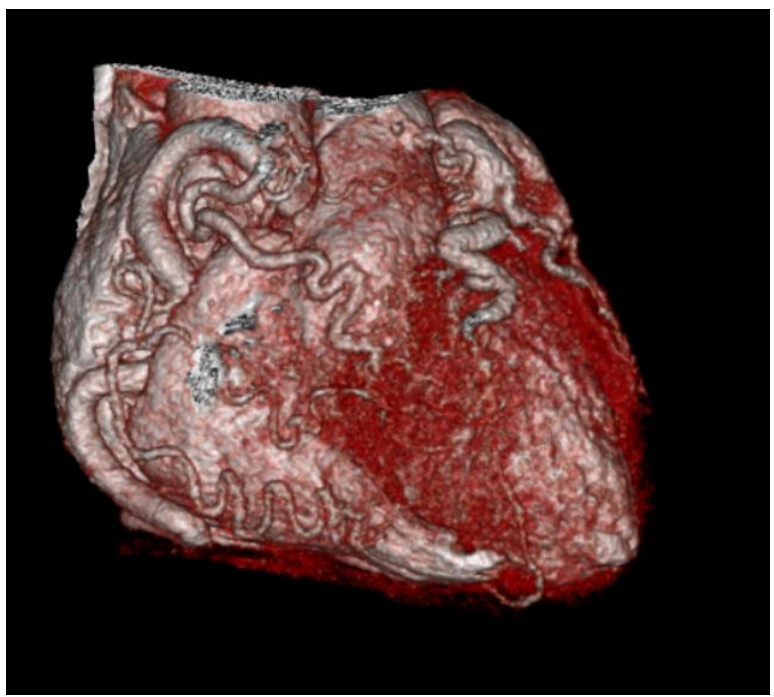

Şekil 3.

Koroner BT Anjiyografi görüntüsü

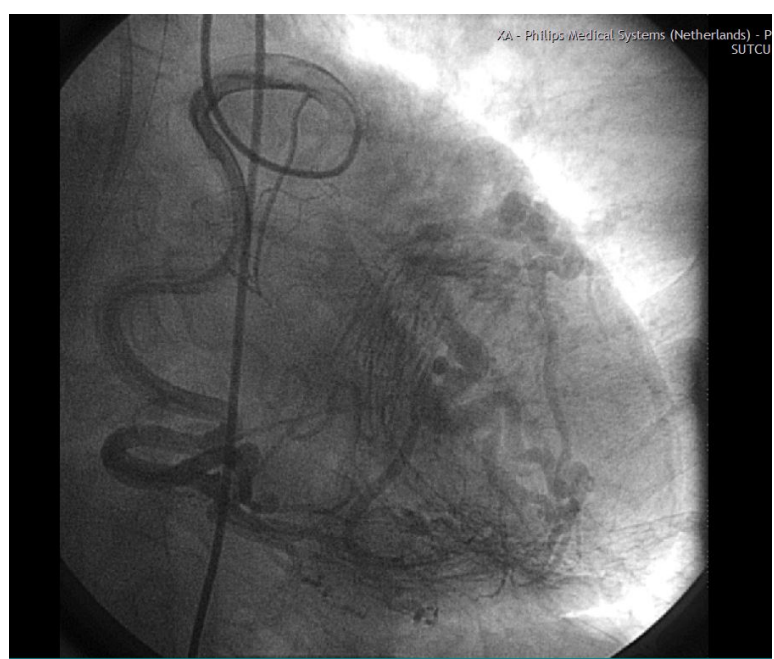

Şekil 4.

Koroner anjiyografide kollateral dolasim 


\section{Tartışma}

ALCAPA, 300.000 canlı doğumda 1'i etkileyen ve doğumsal kalp defektlerinin yaklaşı 1 \% 0.5 'ini temsil eden nadir bir hastalıktır ${ }^{3}$. ALCAPA'nın semptomlarının ortaya çıkışı ve tanısı, pulmoner vasküler rezistansa, sağ ve sol koroner arter sistemleri arasında kollateral damarların varlığına bağlı olarak değişir. ALCAPA'lı yetişkin hastalar anjina, efor dispnesi veya ani kalp ölümü ile ortaya çıkabilir veya ALCAPA tesadüfen bulunabilir ${ }^{4}$. Görüntüleme teknolojisi ilerledikçe, koroner bilgisayarlı tomografi, manyetik rezonans görüntüleme ve miyokard perfüzyon görüntüleme gibi invazif olmayan teknikler, koroner arter malformasyonlarını değerlendirmek ve böylece ALCAPA'nın teşhisine yardımcı olmak için kullanılmiştır ${ }^{5}$. ALCAPA hastalarının fetal ve erken bebeklik dönmelerinde, Pulmoner arterden (PA) LAD'ye yüksek PA basıncı nedeniyle PA'dan antegrad akışa neden olabilir. Bununla birlikte, PA basıncı doğumdan sonra azaldıkça, LAD - PA şantı meydana gelir. Bu, LAD'nin beslediği alana zarar veren, sol ventrikülün perfüzyonunu etkileyen ve subendokardın iskemisine yol açan gerçek yüksek akımlı, düşük basınçlı şanttır. Bu yüksek hızlı, düşük basınçlı akım nedeniyle epikardiyal arter genişler. İyi gelişmiş kollateral dolaşım, hipoperfüzyonunu ve akut semptomları önler. Anterolateral miyokard bölgesinde iskemi geliştiğinden DI, aVL ve V4-V6'da patolojik Q dalgaları görülebilir. Kollateral dolaşımı iyi gelişmiş olan hastalarda çeşitli EKG değişiklikleri izlenebilir ${ }^{6}$. Tipik EKG bulguları olan hastalarda sol ventrikül (LV) işlev bozukluğunun eşlik etmesi anormal koroner arter varlığını işaret edebilir ${ }^{7}$. İntrauterin dönemde, sol koroner arter basıncı, pulmoner arter basıncindan daha yüksek olması nedeniyle pulmoner arterden antegrad kan akımına sahiptir. Pulmoner direnç ve oksijen içeriği yenidoğan fazında pulmoner arter sisteminde düşerken, miyokard düşük oksijen içeriğine sahip kanla perfüze edilir. Sonunda, sol koroner sistemin dallarını beslemek için sağ koroner arterden kollateraller gelişir ve sol koroner sistemdeki basınç artar. $\mathrm{Bu}$, sol koroner sistemden düşük basınçlı akciğer sistemine akışın tersine dönmesine neden olur. $\mathrm{Bu}$ fenomen genellikle "koroner çalma" olarak kabul edilir. Klinik spektrum dört türe ayrılabilir:

(1) İnfantil tip: ölüm sonrası vakaların gözden geçirilmesinde, Kaunitz, 2 ay civarında duktus arteriosusun kapanmasının semptomların gelişimine neden olduğunu belirtti ${ }^{8}$. Bu durum sol ventrikül iskemisine yol açar. Semptomların yaklaşık \%90'1, 2 ila 4 ay arasında ortaya çıkmakta, zayıf büyüme, taşipne, bol terleme ve anjina benzeri atak belirtileri ortaya çıkmaktadır. Semptomatik olan ve tedavi edilmeyen bebeklerin yaklaşık\%90'ı yaşamın ilk iki yılında ölmektedir.
(2) Asemptomatik yetişkin tipi: ALCAPA ile bebeklik döneminde sağ kalan yetişkinlerin çoğunun geniş bir kollateralizasyona ve genişlemiş bir RCA'ya sahip olduğu bulunmuştur. Bebeklik çağında, RCA'nın sadece arka değil, aynı zamanda lateral duvarı beslediği varsayılmaktadır. $\mathrm{Bu}$ hastalarda kollateral kan akımı nedeniyle hafif üfürüm veya akciğer grafisinde hafif mitral yetersizliği veya rastlantısal kardiyomegali vardir.

(3) Semptomatik yetişkin tipi: $\mathrm{Bu}$ yetişkinler, kollaterallerden düşük basınçlı pulmoner artere veya stres sırasında ortaya çıkan koroner çalmaya artan akış nedeniyle anjina belirtileri gösterir. Bu hastalarda orta ila şiddetli mitral yetersizliği de olabilir. Mitral yetersizliği sol ventrikül dilatasyonu veya papiller kas fonksiyon bozukluğu nedeniyle ortaya çıkar?

(4) Ani kardiyak ölüm: yetişkin vakaların yaklaş1k \%85'inde önceden kardiyak semptomları yoktur. Histolojik çalışmalar, ölümcül ventriküler taşiaritmilerin öncüsü olduğuna inanılan miyokard dokusunda önemli miktarda canlı ancak depresif kasılma dokusunu ve değişken miktarda fibrozisi göstermiştir ${ }^{10}$.

Pulmoner arterden anormal bir koroner arteri tamir etmek için çeşitli cerrahi yöntemler kullanılabilir, bunların hepsi iki koroner arterli bir sistem kurmayı amaçlar. En yaygın yöntemlerden biri, koroner arterin aort içine doğrudan reimplantasyonudur. Diğeri aorttan kan akışını LCA'ya (Takeuchi) yönlendiren bir aortopulmoner pencere yaratmaktır. $\mathrm{Bu}$ işlemlerden sonra ventrikül fonksiyonları ne kadar bozulmuş olursa olsun, miyokard fonksiyonu hızla iyileşebilir ${ }^{11}$.

ALCAPA hastalarında LV fonksiyonu mitral kapak disfonksiyonu ile karakterizedir. Preoperatif mitral kapak yetersizliği önemli bir risk faktörüdür. Ancak, ALCAPA hastalarında mitral kapak onarımı tartışmalıdır. Vouhé ve diğ. , miyokard iskemisinin çözülmesinin papiller kas fonksiyonunun iyileşmesine yol açtığını öne sürmüşlerdir ${ }^{12} . \mathrm{Bu}$ nedenle mitral kapak onarımının ilk başta yapılmaması gerektiğini öne sürdüler. Devam eden mitral kapak yetersizliği olan hastalarda, koroner arter restenozu araştırılmalı ve gerekirse mitral kapak bu aşamada onarılmalıdır. Buna karşın, diğer araştırmacılar, koroner arter reimplantasyonu sırasında eş zamanlı mitral kapak onarımı ve anterolateral kommissural annuloplasti'nin LV fonksiyonlarının erken iyileşmesini arttırdığını iddia etmişlerdir ${ }^{13}$.

ALCAPA nadir ve hayatı tehdit eden bir durum olmakla birlikte yeni tanı yöntemlerinin gelişmesi, yaşlı populasyonda görülme sıklığının artması ile ilişkili$\operatorname{dir}^{14}$. Görüntüleme yöntemleri, özellikle ekokardiyografi, ALCAPA'nın tanı ve takibinde büyük öneme sahiptir. Makroskopik yapının değerlendirilmesi açısından bilgisayarlı tomografik anjiografi doğumsal koroner arter anomalilerini ortaya koymada çok iyi sonuçlar verir. Kollateral dolaşımın oluşumu nedeniy- 


\section{Kerkütlüoğlu, ark.}

le yetişkin çağa ulaşan hastalar asemptomatik olabilir. Bununla birlikte hastalık ilerledikçe kardiyak yapılar değişir, sol kalp genişlemeye başlar, mitral yetersizliğ ortaya çıkar. $\mathrm{Bu}$ hastaların kalp yetmezliği ve ani kardiyak ölüm açısından yüksek riskli oldukları unutulmamalidır.

Etik Kurul Bilgisi:

Olgu sunumu çalışma Etik Kurul onayı gerektirmemektedir.

\section{Kaynaklar}

1. Rodriguez-Gonzalez M, Tirado AM, Hosseinpour R, Soto JS Anomalous origin of the left coronary artery from the pulmonary artery diagnoses and surgical results in 12 pediatric patients. Tex Heart Inst J. 2015;42(4):350-356.

2. Birk E, Stamler A, Katz J, Berant M, Dagan O, Matitiau A, et al. Anomalous origin of the left coronary artery from the pulmonary artery diagnosis and postoperative follow up. Isr Med Assoc J. 2000;2(2):111-114.

3. Karr SS, Parness IA, Spevak PJ. van der Velde ME.Colan SD.Sanders SP Diagnosis of anomalous left coronary artery by Doppler color flow mapping distinction from other causes of dilated cardiomyopathy. J Am Coll Cardiol. 1992;19(6):12711275 .

4. Dilaveris, P, Koutagiar, I, Alexopoulos, N. Secondary prevention of sudden cardiac death in a 65 year untreated alcapa patient. Int J Cardiol 2014; 176: 73-74.

5. Oncel, G, Oncel, D. Anomalous origin of the left coronary artery from the pulmonary artery: diagnosis with CT angiography. J Clin Imaging Sci 2013; 3: 4.

6. Zheng JY, Han L, Ding WH, Jin M, Zhang GZ, Xiao YY, et al. Clinical features and long-term prognosis of patients with anomalous origin of the left coronary artery from the pulmonary artery. Chin Med J (Engl) 2010;123(20):28882894.

7. Ceylan Ö, Örün UA, Koç M, Özgür S, Dogan V, Karademir S, et al. Anomalous coronary artery originating from the pulmonary artery a report of four cases. Türk Gögüs Kalp Damar Cerrahisi Dergisi. 2013;21:122-126.

8. P. E. Kaunitz, "Origin of left coronary artery from the pulmonary artery: review of the literature and report of two cases," American Heart Journal, vol. 33, no. 2, pp. 182-206, 1947.

9. G. Dahle, A. Fiane, and H. Lindberg, "ALCAPA, a possible reason for mitral insufficiency and heart failure in young patients," Scandinavian Cardiovascular Journal, vol. 41, no. 1, pp. 51-58, 2007.

10. B. Shivalkar, M. Borgers, W. Daenen, M. Gewillig, W. Flameng, "ALCAPA syndrome: an example of chronic myocardial hypoperfusion?" Journal of the American College of Cardiology, vol. 23, no. 3, pp. 772-778, 1994.

11. Alsoufi B, Sallehuddin A, Bulbul Z, Joufan M, Khouqeer F, Canver CC, et al. Surgical strategy to establish a dual-coronary system for the management of anomalous left coronary artery origin from the pulmonary artery. Ann Thorac Surg. 2008;86(1):170-176.

12. Vouhé PR, Tamisier D, Sidi D, Vernant F, Mauriat P, Pouard P, et al. Anomalous left coronary artery from the pulmonary artery results of isolated aortic reimplantation. Ann Thorac Surg. 1992;54(4):621-626.

13. Huddleston CB, Balzer DT, Mendeloff EN. Repair of anomalous left main coronary artery arising from the pulmonary artery in infants long-term impact on the mitral valve. Ann Thorac Surg. 2001;71(6):1985-1988.

14. Yau JM, Singh R, Halpern EJ, Fischman D. Anomalous origin of the left coronary artery from the pulmonary artery in adults: a comprehensive review of 151 adult cases and a new diagnosis in a 53-year-old woman. Clin Cardiol. 2011 Apr;34(4):204-10. 